\title{
Questões metodológicas e ferramentas de pesquisa nos estudos em Aquisição da Linguagem
}

\author{
Methodological questions and tools of research in Language Acquisition \\ Rosângela Nogarini Hilário \\ Universidade Federal de São Paulo - Guarulhos - São Paulo - Brasil \\ Alessandra Del Ré \\ Universidade Estadual Paulista - Araraquara - São Paulo - Brasil
}

$\diamond$

\begin{abstract}
Resumo: Este artigo visa a apresentar, de forma resumida, aspectos relacionados à metodologia voltada para uma abordagem dialógica e discursiva nos estudos em Aquisição da Linguagem. Nele discutimos quatro aspectos centrais envolvidos nessa temática: i) a relação entre a metodologia aplicada, as questões de pesquisas e a abordagem teórica, ii) algumas ferramentas de transcrição e análise disponíveis e a aplicação das mesmas aos estudos de cunho mais qualitativo, iii) as categorias de análise - linguísticas e discursivas, iv) a necessidade de (e a dificuldade em) comparar as produções da criança. Com isso, pretende-se introduzir na discussão acerca das escolhas metodológicas, as questões concernentes a uma abordagem que considera a relação entre língua e discurso.
\end{abstract}

Palavras-chave: Aquisição da Linguagem; Abordagem dialógica e discursiva; Pesquisas qualitativas e quantitativas

\begin{abstract}
This article aims to present, in summary, some aspects related to the methodology in a dialogical and discursive approach in Language Acquisition studies. It will be discussed four essential aspects involved in this topic: i) the relation between the applied methodology, the research questions and the theoretical approach, ii) some of the available transcription and analysis tools and their usage on qualitative studies, iii) the categories of analysis - linguistic and discursive, iv) the need (and the difficulty) to compare the children's productions. Therefore, it is intended to introduce in the discussion about the methodological choices, the questions related to an approach which considers the relation between language and discourse.
\end{abstract}

Keywords: Language Acquisition; Dialogical and discursive approach; Qualitative and quantitative researches

\section{Introdução}

Desde que a área de Aquisição da Linguagem surgiu, pelas fronteiras que ela sempre estabeleceu com áreas afins (Psicologia, Fonoaudiologia, Neurolinguística etc.), muitas questões referentes à metodologia a ser adotada na coleta e análise dos dados se colocaram. Estas questões refletem as heterogeneidades teóricas que cercam a área, isto é, estão diretamente relacionadas com as várias formas de se conceber tanto a linguagem enquanto objeto de estudo quanto os estados inicial e final do processo de aquisição.

Os principais textos propostos com o intuito de dar um panorama geral sobre os estudos em Aquisição da
Linguagem (CORREA, 1999; SCARPA, 2001; SCLIARCABRAL, 1989) trouxeram informações relevantes sobre pesquisas fundamentadas na Teoria Behaviorista, na Teoria Linguística de Chomsky, no Construtivismo Piagetiano, no Sócio-interacionismo de Vygotsky e no Interacionismo proposto por de Lemos. Dois trabalhos de De Lemos $(1994,1995)$ apontaram para uma possível reflexão dialógico-discursiva, os de Silva $(2007,2009)$ para um olhar enunciativo, todavia, uma abordagem dialógica e discursiva, que considere a unidade entre língua e discurso, e as implicações metodológicas de tal abordagem ainda não foram exploradas.

Neste artigo, nossa intenção é refletir, tendo em vista os estudos em aquisição da linguagem, sobre as relações 
entre a metodologia empregada e as questões de pesquisas levantadas, bem como sobre a fundamentação teórica adotada, com especial atenção àquelas que partem de uma abordagem dialógica e discursiva, à qual nos filiamos.

Para tanto, esse texto se organiza da seguinte maneira: na primeira parte discutimos a impossibilidade de se ter, a priori, uma metodologia de coleta de dados que contemple todas as pesquisas igualmente, visto que as próprias questões de pesquisa orientam o pesquisador para uma coleta longitudinal ou transversal, naturalística ou experimental, e para análises qualitativas ou quantitativas. Na segunda parte, nosso olhar se volta para algumas ferramentas computacionais disponíveis para a análise dos dados. Na terceira parte, nos referimos aos fios condutores que regem nosso olhar na definição de categorias de análise, tendo em vista a relação entre língua e discurso. Na quarta parte, abordamos a problemática da comparação das produções das crianças em uma mesma língua e em língua diferentes. Por fim, traremos as palavras finais, que, longe de serem conclusões acerca do tema aqui levantado, fecham (apenas provisoriamente) a discussão que propomos neste artigo e, principalmente, apontam para novas reflexões na área.

\section{Sobre a impossibilidade de se ter, a priori, uma metodologia universal}

Segundo Correa (1999), embora haja grande variação entre as línguas e entre os indivíduos, observa-se, no processo de aquisição da linguagem, um padrão de desenvolvimento comum aos diferentes indivíduos nas diferentes línguas, o que remeteria ao que, na linguagem, é comum à espécie humana. Para a autora, "cabe a uma teoria da aquisição da linguagem explicar esse fato, considerando de que modo a aquisição de uma língua específica pode elucidar o processo pelo qual a aquisição espontânea de qualquer língua humana se realiza" (CORREA, 1999, p. 340). A tarefa - por si só, desafiadora -, revela-se ainda mais complexa quando se considera a ausência de consenso quanto ao modo de se conceber a língua a ser adquirida e o ponto de partida do processo de aquisição.

Embora a área de aquisição da linguagem tenha certa tradição nos estudos descritivos, longitudinais e naturalísticos - como, por exemplo, a publicação de Darwin em 1877 sobre o desenvolvimento (inclusive da linguagem) de seu filho -, a partir dos anos 1970 as pesquisas direcionadas pela Teoria Linguística de Chomsky começaram a buscar, a partir de estudos experimentais, respostas para a questão da aquisição da linguagem. À luz do gerativismo de Chomsky, o problema da aquisição seria originalmente concebido como um problema de identificação da língua materna pela criança (seleção de uma língua num conjunto de línguas possíveis) (cf. CORREA, 1999). Trata-se de olhares diferentes para objetos diferentes, já que os dados naturalísticos, mais comuns em pesquisas qualitativas, sustentam principalmente análises sobre a produção linguística da criança, enquanto os dados experimentais, bastante comuns em pesquisas transversais e quantitativas, possibilitam a análise do processamento linguístico, bem como da percepção e compreensão.

Os estudos experimentais têm a vantagem de possibilitar o controle sistemático de variáveis. Isso, porém, não garante que os resultados sejam inquestionáveis, como aponta Grolla (2009). A autora discute algumas metodologias experimentais utilizadas em pesquisas da área, como método da produção eliciada, a tarefa de julgamento de valor de verdade e a tarefa de julgamento de gramaticalidade. Aponta, ainda, que fatores extralinguísticos, como memória, uso de construções restritas a contextos discursivos específicos e proeminência de certas figuras que compõem os experimentos, podem comprometer os resultados. Para a autora, o grande avanço dos estudos em aquisição da linguagem se deve, principalmente, às sofisticadas metodologias empregadas, com experimentos que permitem ao pesquisador vislumbrar o conhecimento linguístico da criança a partir de dados que dificilmente seriam flagrados em estudos naturalísticos. No entanto, é necessário estar atento não só à adequação do método à estrutura estudada, mas também ao contexto discursivo em que essas construções são apresentadas nos experimentos e aos aspectos extralinguísticos que possam interferir nos resultados.

Além das questões discutidas por Grolla (2009), consideramos conveniente levantar outras, igualmente relevantes. Como dissemos, os estudos experimentais, especialmente os filiados à Teoria Linguística chomskyana, buscam investigar, principalmente, a percepção e a compreensão linguística da criança. Os dados de produção, nessa concepção teórica, não dariam conta de explicitar a competência linguística da criança. O controle sistemático de variáveis permite a manipulação dos experimentos a fim de garantir que determinadas construções sejam investigadas. Sabe-se, no entanto, que a entrada da criança na linguagem não se dá em um ambiente onde se possa controlar variáveis. Ao nascer, a criança está imersa em um complexo mundo de sentidos, sendo vista como interlocutora mesmo antes de atuar como tal. Sendo assim, questiona-se: até que ponto os resultados obtidos através do controle sistemático de variáveis em situações experimentais podem, de fato, fornecer respostas sobre a entrada da criança na linguagem, visto que a linguagem contempla os mal entendidos, as ambiguidades, as correções, as reformulações, a incompletude... 
Em uma abordagem dialógica e discursiva, entende-se a aquisição da linguagem muito mais como a entrada da criança em um universo de sentido, no discurso, do que como a emergência de categorias linguística na fala infantil. Aliás, até mesmo as categorias da língua estão, nessa perspectiva, submetidas ao discurso e à construção de um sentido compartilhado pelos sujeitos (entendidos como sujeitos discursivos, mas também como interlocutores). Assim, não nos parece razoável, dentro dessa perspectiva, analisar qualquer produção linguística que não possa ser vista dentro de um quadro mais amplo de diálogo e de interação. Com isso, uma metodologia de coleta e análise de dados se delineia: o diálogo, presente em sentido estrito na interação direta entre mãe e criança, mas também presente em sentido amplo quando considerados os discursos que comparecem na fala da mãe (e da criança), torna-se unidade de análise. Não se trata da análise da troca de turnos de fala - embora isso também seja possível -, mas da presença de outras vozes, outros discurso, constituindo a fala da criança. Cabe ainda ressaltar a necessidade de se considerar os gêneros do discurso como o lugar de entrada da criança na linguagem. As análises extrapolam os limites das categorias estritas de língua, sendo assim incorporadas categorias extralinguísticas e discursivas que considerem os tipos de discurso (de enunciado), o encadeamento dos enunciados, a retomada, a troca de papéis, a gestualidade etc.

Um exemplo representativo dessa perspectiva, baseada nos escritos de Bakhtin e do Círculo (BAKHTIN, 1993, 1997a, 1997b; BAKHTIN/VOLOSHINOV, 2006; VOLOSHINOV, 1976), é o trabalho de Orvig et al. (2013) sobre a aquisição dos determinantes definidos e indefinidos em francês. Os autores analisaram os efeitos de fatores pragmático-discursivos na escolha de determinantes por 24 crianças francesas, observadas em diálogos espontâneos em casa e na escola (creche), entre 1;10 e 3 anos, em um corpus transversal e longitudinal. Os resultados mostram que os padrões de distribuição dos determinantes dependem mais de fatores discursivos e dialógicos, como introdução e reativação do referente, desenvolvimento do tema, resposta, auto-repetição ou retomada do enunciado do interlocutor, do que do nível de desenvolvimento sintático e morfológico. Concluem, assim, que o determinante não tem um valor intrínseco; seu valor é, pois, resultado da relação entre a unidade linguística e o contexto sentencial e discursivo. Observase, então, a necessidade da interface entre o pragmáticodiscursivo e o linguístico, não como duas linhas de desenvolvimento dissociadas uma da outra, mas como um desenvolvimento unificado.

Os trabalhos de Orvig, assim como os de François (1994, 2004, 2006, entre outros), têm inspirado pesquisas também no Brasil, como os estudos sobre o humor na fala de crianças brasileiras (DEL RÉ, 2011), sobre as primeiras condutas argumentativas (VIEIRA, 2011), acerca da aquisição e uso do morfema de plural por crianças monolíngues e bilíngues (HILÁRIO, 2013) e sobre a auto-referência e a referência ao outro na fala de uma criança bilíngue (BULLIO, 2014), dentre outros.

Coletas longitudinais e naturalísticas têm se mostrado mais pertinentes às questões colocadas pelos pesquisadores que assumem uma abordagem dialógica e discursiva. O grupo NALíngua/CNPq, ao qual pertencemos/coordenamos, por exemplo, em sintonia com pesquisadores franceses dos grupos DIAREF (coordenado pela Profa. Dra. Anne Salazar Orvig) e COLAJE (coordenado pela Profa. Dra. Aliyah Morgenstern), ambos da Université Sorbonne Nouvelle - Paris 3, tem desenvolvido um trabalho de coleta desses dados longitudinais e naturalísticos - com 6 crianças brasileiras, filmadas mensalmente, em situações cotidianas (banho, refeição, brincadeiras...). Pretende-se, futuramente, acompanhar, além da linguagem oral dessas crianças, sua aquisição da escrita, com filmagens em espaço escolar. Trata-se de um conjunto de dados extremamente extenso, que exige, portanto, um longo trabalho de transcrição.

Seria pouco produtivo para a área manter um trabalho dessa natureza, que exige tanta disponibilidade por parte do pesquisador - trata-se de coletas mensais de cerca de uma hora de duração com cada uma das crianças, desde o nascimento até os 7 anos de idade - e por parte do transcritor, apenas para uso dos pesquisadores do grupo. Em se tratando de dados naturalísticos, pode-se presumir que eles podem contemplar inúmeras questões de pesquisa - desde aquelas mais voltadas para questões linguísticas (aquisição morfológica, fonológica, desenvolvimento sintático e lexical etc.) até as de caráter mais discursivo (humor, argumentação, negação, ironia etc.). Diante disso e considerando-se o possível interesse da comunidade científica (inter)nacional, a transcrição tem sido feita a partir de um programa de computador (CLAN) que leva em conta um conjunto de normas de transcrição (CHAT) ${ }^{1}$, ambos formulados tendo em vista os dados de aquisição. Com isso, abre-se a possibilidade de compartilhamento dos dados a partir de uma espécie de "língua franca".

\section{Acerca de (algumas) ferramentas computacionais disponíveis}

O programa CLAN foi desenvolvido em meados dos anos 1980 por Bryan MacWhinney e colaboradores. Ele

\footnotetext{
A ferramenta CHAT, do programa CLAN, está disponível na plataforma CHILDES (MacWhinney, 2000) e tem acesso gratuito. Esse tipo de transcrição permite que o enunciado transcrito esteja alinhado ao video correspondente a essa produção. Cada hora de gravação leva cerca de 30 horas de trabalho por parte do transcritor.
} 
faz parte de uma plataforma intitulada Child Language Data Exchange System (CHILDES), nela constando dados de crianças em aproximadamente 28 línguas diferentes.

Os dados são acessíveis aos pesquisadores, podendo-se fazer o download tanto da mídia (áudio ou vídeo) quanto da transcrição. A plataforma conta ainda com um conjunto de normas ${ }^{2}$ de transcrição (CHAT), que, em conjunto com o programa CLAN, permite a análise automática dos dados a partir de comandos específicos - análise da frequência lexical (types e tokens), análise morfológica, busca de elementos linguísticos específicos etc. O CHAT, como dissemos, funcionando como uma espécie de "língua franca", garante uma uniformidade na transcrição dos dados, aspecto bastante complicado se considerarmos que as transcrições dos dados de crianças se baseiam, muitas vezes, em padronizações estabelecidas em projetos que se restringiam à fala adulta (como o NURC (CASTILHO, PRETI, 1986, 1987), por exemplo) ou pelos próprios pesquisadores, tendo, assim uma variação muito grande.

O CHILDES vem sendo abastecido, ao longo dos anos, por pesquisadores do mundo inteiro. Para que a análise morfológica possa ser feita, é necessário que a língua em questão possua um documento chamado Gramática MOR. Com esse documento, é possível gerar, automaticamente, uma linha de análise morfológica (\%mor) e, a partir dela, fazer a contagem da média de morfemas (ou palavras) por enunciado (MLU - Mean length of utterance, ou EME - Extensão média do enunciado). Esse trabalho (criação dos algoritmos para estabelecimento da gramática MOR para o Português do Brasil (PB)) vem sendo desenvolvido pela equipe da Profa. Dra. Leonor Scliar-Cabral (2012). Esse grupo foi também responsável pelo primeiros conjunto de dados em PB disponibilizados no CHILDES, porém apenas o áudio está disponível.

No entanto, é necessário ponderar se análises estritamente automáticas garantirão resultados satisfatórios, considerando os dados de aquisição. Sabe-se que, na fala da criança, as categorias linguísticas (alvo do programa e de tais análises) nem sempre aparecem como são produzidas na fala adulta. Um exemplo desse debate foi apresentado em Del Ré e Hilário (2013), onde se discutiu a consideração ou não da presença de um morfema de plural para a contagem do MLU em elementos, a princípio, invariáveis, como advérbios, por exemplo.

Para pesquisadores interessados na depreensão de gramáticas emergentes, bem como em análises de cunho mais quantitativo, a gramática MOR é um recurso ímpar. Porém, o programa CLAN tem se mostrado uma ferramenta importante também para análises mais discursivas, especialmente por possibilitar o alinhamento da linha de transcrição ortográfica - linha principal - ao vídeo, podendo-se ainda adicionar linhas de informações acerca da ação desenvolvida no momento da produção dos enunciados, linha de produção gestual etc. Com isso, é possível fazer uma análise considerando não apenas o trabalho do transcritor (que, por si só, já se configura como uma interpretação da fala da criança e da cena enunciativa), mas do próprio registro em vídeo. Através de comandos específicos, é possível ainda efetuar buscas de enunciados em contexto, isto é, considerando os enunciados anteriores e posteriores.

Outra ferramenta bastante importante, especialmente se considerarmos uma abordagem multimodal, é o programa computacional ELAN.

Assim como o CLAN, o software ELAN (Eudico Linguistic Annotator), além de ser gratuito e compatível com Windows, Linux e Mac, permite igualmente ao usuário fazer anotações sincronizadas a um vídeo selecionado. Trata-se de um programa de fácil utilização, com constantes atualizações e discussões em fóruns na própria página ${ }^{3}$. A diferença do ELAN em relação ao CLAN é que suas janelas permitem uma descrição mais detalhada de cada um dos gestos a serem analisados, por exemplo, direção do apontar, movimento dos olhos etc. Esse software tem sido bastante utilizado em pesquisas que enfocam a multimodalidade, assim como a aquisição de linguagem por crianças surdas - citamos, por exemplo, os trabalhos de Quadros, Lillo-Martin e Pichler (2013), Christmann, Domingo, Oliveira e Quadros (2014) e a obra organizada por Colletta, Millet e Pellenq (2010).

Aliados a esses programas de transcrição e análise, outros, como o PRAAT ${ }^{4}$ e o PHON $^{5}$, ajudam nas análises prosódicas, tão importantes quando se trabalha, por exemplo, com a questão da ironia (a prosódia tem um papel fundamental na construção do sentido), bem como na análise da aquisição fonológica.

\section{Sobre as categorias de análise}

Dentro de uma perspectiva dialógica e discursiva, o contexto tem um papel crucial na interpretação dos enunciados infantis, mas não só. É necessário que o pesquisador mantenha uma distância necessária, a fim de não atribuir às produções da criança um sentido que extrapole o diálogo, isto é, um sentido proveniente da análise linguística e não da relação entre a fala da criança

\footnotetext{
2 O grupo GEALin/NALingua desenvolveu uma versão reduzida em português do manual fornecido em inglês (cerca de 50 páginas) e outra com os comandos, ambos publicados em 2012 (DEL RÉ, HILÁRIO, MOGNO, 2012; HILÁRIO et al, 2012).

$3<$ http://www.lat-mpi.eu/tools/elan/>.

$4<$ www.fon.hum.uva.nl/praat $>$.

$5<$ childes.psy.cmu.edu/phon $>$.
} 
e de seu interlocutor adulto. Assim, faz-se necessário considerar de que forma o interlocutor interpretou a fala da criança, ainda que, observando a posteriori as transcrições, o analista verifique que essa interpretação não esteja de acordo com o que foi dito. O fato é que é a resposta do interlocutor, na interação com a criança, que guiará o diálogo.

Às vezes, a forma ortográfica geralmente utilizada para a análise dos dados não é suficiente. Nesse caso, a inserção de uma linha de transcrição fonética (no programa CLAN indicada como \%pho) é imprescindível - aliás, a transcrição fonética é altamente indicada para os enunciados da criança nos corpora disponibilizados na plataforma CHILDES.

O dilema de onde partir para analisar os dados da criança continua. Sabemos que não é possível olhar para os dados da criança a partir de um ponto de vista adulto, do que o adulto produz. Por outro lado, ainda que seja possível encontrar alguns "padrões" na fala das crianças, não acreditamos que seja possível constituir uma gramática para todas as crianças (como quis Chomsky), já que, do nosso ponto de vista, cada criança entra na linguagem de uma forma diferente. Diante disso, restanos partir da gramática adulta, que nos serve apenas como referência, mas com o cuidado de não compará-la em termos de observar aquilo que falta na linguagem da criança.

As categorias de análise estão, portanto, apoiadas tanto em categorias linguísticas (tais quais apresentadas em uma gramática adulta) quanto em categorias discursivas, que considerem a relação entre a fala da criança e a do interlocutor adulto no diálogo.

Essas ideias se organizam no que chamamos de fios condutores da análise e dizem respeito aos elementos linguístico-discursivos a serem observados. A proposta não é, no entanto, de reduzir as análises a eles. Vale dizer que esses fios condutores não são elaborados a priori. Eles são o resultado de um trabalho de análise minucioso que já foi realizado, no caso do que foi elaborado pelo grupo DIAREF, ao longo de aproximadamente 10 anos de pesquisas com crianças francesas. A cada vez que surgem novos dados, verifica-se se esses fios condutores são suficientes - ou não - para dar conta da análise proposta. Obviamente eles nunca são, pois ainda que se trate da mesma língua(gem)/cultura - do francês, por exemplo -, novas categorias podem ser incorporadas, levando-se em consideração o fenômeno estudado e a especificidade do corpus; além disso, em se tratando de uma outra língua(gem)/cultura - no caso do PB, por exemplo -, outras especificidades surgirão. Sendo assim, o pesquisador, a cada vez que se depara com novos dados, reorganiza os fios condutores, modifica-os e reelabora-os também considerando as particularidades de sua pesquisa.
Como exemplo, citamos o projeto coordenado pela Profa. Dra. Anne Salazar Orvig sobre a aquisição de expressões referenciais (DIAREF/ANR-09-ENFT$0555)^{6}$, cujas categorias de análise serviram de apoio para a pesquisa, anteriormente citada, de Bullio (2014) ${ }^{7}$ acerca da autorreferência e da referência ao outro nas produções de uma criança bilíngue (PB e francês). Os pronomes foram, obviamente, alvo de análise, porém o comportamento das duas línguas em questão são bastante particulares (o paradigma pronominal do PB inclui, por exemplo, o pronome nulo, inexistente em francês). Esse aspecto acarreta mudanças também na forma como a fala do outro é retomada, impondo adaptações nas categorias de análise, tanto para o PB quanto para o francês, já que a criança está adquirindo ambas as línguas concomitantemente - o que implica, ainda, considerar a possível interferência de uma língua sobre a outra.

Categorias discursivas foram também incorporadas às nossas análises (Hilário, 2013), sobre a aquisição e emprego do morfema de plural. Observou-se, com isso, que a produção dos primeiros sintagmas nominais plurais, na fala da criança, está diretamente relacionada a tipos específicos de enunciados (os descritivos, por exemplo) e a atividades nas quais os interlocutores atuam (jogos, por exemplo).

Embora esses fios condutores garantam um olhar atento para a relação entre aspectos linguísticos e discursivos na análise das produções da criança - inclusive de diversas crianças em diversas línguas -, o problema da comparação dessas produções - especialmente quando pensamos em um parâmetro para tal comparação permanece, ainda, sem uma solução definitiva.

\section{Da necessidade de (e dificuldade em) analisar e comparar as produções das crianças}

As pesquisas transversais, nas quais são analisados dados de diversos sujeitos num mesmo momento e/ou em momentos diferentes, e as pesquisas com sujeitos bilíngues, nas quais um mesmo sujeito produz em diferentes línguas, impõem aos estudiosos da área um problema crucial: afinal, como analisar e comparar dados de crianças que, apesar de terem a mesma idade, têm desenvolvimentos tão diferentes?

\footnotetext{
6 Projeto "L'acquisition en dialogue des expressions référentielles: approches multidimensionnelles", coordenado por Anne Salazar Orvig, docente e pesquisadora na Université Sorbonne Nouvelle - Paris 3, nas áreas de Aquisição da Linguagem e Análise do Discurso. <http://www. univ-paris3.fr/salazar-orvig-anne-29869.kjsp>

7 O capítulo que citamos aqui traz apenas um recorte de estudo mais amplo, que será apresentado na íntegra em sua tese de doutorado, com defesa prevista para setembro de 2014
} 
Uma alternativa bastante utilizada é o MLU (mean lenght of utterance), nomeado no Brasil como EME (extensão media do enunciado). Essa medida tem sido proposta e utilizada para caracterizar o desenvolvimento linguístico da criança, independente de sua idade cronológica. O MLU pode ser calculado tanto em morfemas (MLUm: media de morfemas por enunciado, considerando um total de 100 enunciados) quanto em palavras (MLUw: media de palavras por enunciado, considerando um total de 100 enunciados).

Um estudo desenvolvido com crianças americanas com desenvolvimento típico (PARKER, BRORSON, 2005) demonstrou que os resultados do MLUm e MLUw são perfeitamente correlacionados, o que sugere que o MLUw pode ser usado de forma tão eficaz quanto o MLUm como medida do desenvolvimento da linguagem da criança.

Em estudo semelhante, Arif e Bol (2009), investigaram a correlação entre o MLUm e o MLUw em crianças com e sem distúrbios de linguagem, cujos dados foram retirados do CHILDES. Concluíram, assim como Parker e Brorson, que ambos são correlatos e que o MLUw apresenta-se como uma opção interessante, pois é mais fácil e menos técnico em termos de complexidade gramatical.

Ainda que o cálculo da média de palavras por enunciado seja, a princípio, um procedimento mais simples do que o cálculo da média em morfemas, o próprio entendimento do que possa ser considerado uma palavra na produção da criança não é um consenso entre os pesquisadores, como aponta Aimard (1998) e ScliarCabral (2012). Sendo assim, a questão da comparação entre as produções das crianças permanece em aberto.

\section{Palavras finais}

Neste artigo, nosso objetivo, conforme proposto, foi levantar algumas questões metodológicas relacionadas a uma abordagem dialógico-discursiva, que adotamos em nossos trabalhos, discutindo ainda as possibilidades de complementação das análises a partir do uso - ou não - de algumas ferramentas de pesquisa.

Acreditamos que haja ainda muitos mitos - a favor e contra - o uso de ferramentas tecnológicas, como as que citamos neste trabalho, para a elaboração de pesquisas na área de aquisição. Tentamos aqui elucidar alguns deles mostrando que, ao contrário do que muitas pessoas acreditam, essas ferramentas não representam uma solução "mágica" para os estudos, mas podem auxiliar os pesquisadores na sistematização dos dados, em uma análise preliminar dos mesmos. Por outro lado não representam um "perigo" para os estudos, desde que o pesquisador permaneça fiel ao trabalho que ele deve executar, um trabalho mais minucioso que vai além das ferramentas.

Outra tentativa deste artigo foi a de elucidar algumas questões que muitas vezes são alvo de críticas dentro e fora da área: a interpretação dos dados (que deve sempre se pautar naquela dada pelos interlocutores), o uso de categorias de análise (que não existem a priori, mas são o resultado de um trabalho árduo e minucioso que se renova a cada novo dado), o pareamento de resultados de dados de crianças que são analisadas pelo mesmo pesquisador (a idade não pode ser um bom parâmetro já que as crianças entram na língua(gem) de modos diversos). Para a maioria dessas questões não há uma solução definitiva, mas acreditamos que seja necessário explicitá-las a fim de que se possa refletir mais sobre elas.

Fica, deste modo, o convite para futuras reflexões.

\section{Referências}

AIMARD, P. O surgimento da linguagem na criança. Porto Alegre: ArtMed, 1998.

ARIF, H.; BOL, G. Counting MLU in morphemes and MLU in words in a normally developing child and child with a language disorder: A comparative study. Dhaka University Journal of Linguistics, 1, Sep. 2009. Available from: <http://www. banglajol.info/index.php/DUJL/article/view/3345> (access: Aug. 30, 2014).

BAKHTIN, M. Para uma filosofia do ato. Tradução de Carlos Alberto Faraco e Cristóvão Tezza (tradução não revisada, exclusiva para uso didático e acadêmico) da edição americana Toward a Philosophy of the Act. Austin: University of Texas Press, 1993.

BAKHTIN, M. O autor e o herói. In: BAKHTIN, M. Estética da criação verbal. Tradução de Maria Ermantina Galvão G. Pereira. 2. ed. São Paulo: Martins Fontes, 1997a. p. 25-220.

BAKHTIN, M. Os gêneros do discurso. In: BAKHTIN, M. Estética da criação verbal. Tradução de Maria Ermantina Galvão G. Pereira. 2. ed. São Paulo: Martins Fontes, 1997 b. p. 261-306.

BAKHTIN, M. (VOLOSHINOV, V. N.). Marxismo e filosofia da linguagem. Problemas fundamentais do método sociológico na ciência da linguagem. Tradução de Michel Lahud e Yara Frateschi Vieira. São Paulo: Hucitec, 2006.

BULliO, P. C.; HILÁRIO, R. N.; BUENO, R. G.; DEL RÉ, A. Bilinguismo e referência. In: DEL RÉ, A., PAULA, L., MENDONÇA, M. C. (Org.). Explorando o discurso da criança. São Paulo: Contexto, 2014. p. 125-144.

CASTILHO, A. T.; PRETI, D. (Org.). A linguagem falada culta na cidade de São Paulo: materiais para seu estudo. São Paulo: T. A. Queiroz; Fapesp, 1986. Vol. 1.

CASTILHO, A. T.; PRETI, D. (Org.). A linguagem falada culta na cidade de São Paulo: materiais para seu estudo. São Paulo: T. A. Queiroz; Fapesp, 1987. Vol. 2.

COLlETTA, J. M.; MILLET, A.; PELLENQ, C. Multimodalité de la communication chez l'enfant. Université StendhalGrenoble III, 2010. 
CORREA, L. M. S. Aquisição da linguagem: uma retrospectiva dos últimos trinta anos. Delta, v. 15, p. 339-383, 1999. http:// dx.doi.org/10.1590/S0102-44501999000300014

CHRISTMANN, K. E.; DOMINGOS, F. K. P.; OLIVEIRA, J. S.; QUADROS, R. M. O software ELAN como ferramenta para transcrição, organização de dados e pesquisa em aquisição da lingua de sinais. Anais do IX Encontro do CELSUL. Palhoça, SC, out. 2010. Disponível em: <http://celsul.org.br/ Encontros/09/artigos/Karina\%20Christmann.pdf $>$. Acesso em: 30 ago. 2014.

DE LEMOS, C. A função e o destino da palavra alheia: três momentos de reflexão. In: BARROS, D. L. P. de; FIORIN, J. L. (Org.). Dialogismo, polifonia, intertextualidade: em torno de Bakhtin. São Paulo: Edusp, 1994. p. 37-43.

DE LEMOS, C. Língua e discurso na teorização sobre aquisição de linguagem. Letras de Hoje, Porto Alegre, v. 30, n. 4, p. 9-28, dez. 1995

DEL RÉ, A. A criança e a magia da linguagem: um estudo sobre o discurso humorístico. São Paulo: Cultura Acadêmica, 2011.

DEL RÉ, A.; HILÁRIO, R. N. Limites e contribuições do uso da EME para pesquisas de cunho qualitativo na aquisição do PB. Prolíngua (João Pessoa), v. 8, p. 121-144, 2013. Disponível em: <http://periodicos.ufpb.br/ojs/index.php/prolingua/article/ view/19327>. Acesso em: 08 ago. 2014.

DEL RÉ, A.; HILÁRIO, R. N.; MOGNO, A. S. Programa CLAN da base CHILDES: normas de transcrição (CHAT) e comandos básicos. In: FERREIRA-GONÇALVES, G.; BRUMDE-PAULA, M. R.; KESKE-SOARES, M. (Org.). Estudos em Aquisição Fonológica. Pelotas: Editora e Gráfica Universitária PREC-UFPel, 2012. Vol. 4. p. 11-30.

FRANÇOIS, F. O que nos indica a "linguagem da criança": algumas considerações sobre a "linguagem". In: DEL RÉ, A. (Org.). Aquisição da linguagem: uma abordagem psicolinguística. São Paulo: Contexto, 2006. p. 183-200.

FRANÇOIS, F. Enfants et récits. Mises em mots et "reste". Lille: Presses Universitaires du Septentrion, 2004.

FRANÇOIS, F. Morale et mise en mots. Paris: L'Harmattan, 1994.

GROLLA, E. Metodologias Experimentais em Aquisição da Linguagem. Estudos da Língua(gem), Vitória da Conquista, v. 7 , n. 2, p. 9-42, 2009.

HILÁRIO, R. N. Um olhar sobre a aquisição do plural nominal em crianças. Tese (Doutorado em Linguística e Língua Portuguesa) - Pós-Graduação em Linguística e Língua Portuguesa, Universidade Estadual Paulista "Julio de Mesquita Filho", Araraquara, 2013.

HILÁRIO, R. N.; MOGNO, A. S.; DEL RÉ, A.; BULLIO, P.; VIEIRA, A. J.; GRECCO, N. A. G.; MELLO, I. A. S.; BUENO, R. G.; FALASCA, P. O CHAT e o CLAN como ferramentas metodológicas nos trabalhos em aquisição da linguagem. In: DEL RÉ, A.; ROMERO, M. (Org.). Na língua do outro: estudos interdiscpilinares em aquisição de linguagens. São Paulo: Cultura Acadêmica, 2012. Vol. 1. p. 329-347.
MACWHINNEY, B. The CHILDES Project: Tools for Analyzing Talk. 3. ed. Mahwah, NJ: Lawrence Erlbaum Associates, 2000.

ORVIG, A. S. et al. Definite and indefinite determiners in French-speaking toddlers: Distributional features and pragmatic-discursive factors. Journal of pragmatics, v. 56, p. 88-112, 2013. http://dx.doi.org/10.1016/j.pragma.2013.03.015

PARKER, M. D.; BRORSON, K. A comparative study between mean length of utterance in morphemes (MLU-m) and mean length of utterance in words (MLU-w). First Language, v. 25, n. 3, p. 365-376, 2005. Available from: <http://www.duluth. umn.edu/csd/documents/FirstLanguage.pdf $>$ (access: Mar. 07, 2011).

QUADROS, R. M.; LILLO-MARTIN, D.; PICHLER, D. C. O que bilíngues bimodais têm a nos dizer sobre desenvolvimento bilíngue? Letras de Hoje, Porto Alegre, v. 48, n. 3, p. 380-388, jul.-set. 2013.

SCARPA, E. M.. Aquisição da Linguagem. In: MUSSALIM, F.; BENTES, A. C. (Org.). Introdução à linguística: domínios e fronteiras. São Paulo: Cortez, 2001. p. 203-232.

SCLIAR-CABRAL， L. Depreensão de uma gramática automática do PB (Plataforma CHILDES). Anais do $X$ Encontro do CELSUL - Círculo de Estudos Linguísticos do Sul UNIOESTE, Universidade Estadual do Oeste do Paraná, Cascavel-PR, 2012. p. 1-13.

SCLIAR-CABRAL, L. Pesquisas sobre aquisição da linguagem no Brasil nos últimos quinze anos. Encontro Nacional de Aquisição da Linguagem, 1989.

SCLIAR-CABRAL, L.; VASILÉVSKI, V. Preparando a gramática automática do português brasileiro. Veredas Online-Especial, PPG Linguística/UFJF, Juiz de Fora, p. 171-186, 2012.

SILVA, C. L. C. A criança na linguagem: enunciação e aquisição. Campinas, SP: Pontes Editores, 2009.

SCLIAR-CABRAL, L. A instauração da criança na linguagem: princípios para uma teoria enunciativa em aquisição da linguagem. Tese (Doutorado em Letras) - Universidade Federal do Rio Grande do Sul, Porto Alegre, 2007.

VIEIRA, A. J. Condutas argumentativas na fala infantil: um olhar sobre a constituição da subjetividade. Dissertação (Mestrado em Linguística) - Pós-Graduação em Linguística e Língua Portuguesa, Universidade Estadual Paulista "Julio de Mesquita Filho", Araraquara, 2011. Disponível em: $<$ http:// portal.fclar.unesp.br/poslinpor/teses/Alessandra_Jaqueline_ Vieira.pdf $>$. Acesso em: 25 jun. 2013.

VOLOSHINOV, V. N. Discurso na vida e discurso na arte. Tradução de Cristóvão Tezza para fins didáticos da versão em inglês de VOLOSHINOV, V. N. Discourse in life and discourse in art (concerning sociological poetics). In: VOLOSHINOV, V. N. Freudianism. A marxist critique. Tradução do russo de I. R. Titunik. New York: Academic Press, 1976.

Recebido: 31 de agosto de 2014

Aprovado: 29 de outubro de 2014

Contatos:ronogarini@gmail.com aledelre@fclar.unesp.br 